\title{
Adenomyoepithelial Adenosis of Breast: A Rare Case Report
}

\author{
Bhaskar MITRA, Mallika PAL, Tarak Nath SAHA, Ashok MAITI
}

Departments of Pathology, Midnapore Medical College, Paschim Medinipore, WEST BENGAL, INDIA

\begin{abstract}
Myoepithelial cells of the breast and their hyperplasia is found in many benign conditions resulting in a spectrum of lesions of myoepitheliosis to myoepithelial carcinoma. We present a rare case of adenomyoepithelial adenosis in a 17-year-old female who presented with a palpable right breast lump. Although considered benign, adenomyoepithelial lesions have a high chance of recurrence due to inadequate excision. Recurrence and even metastasis are therefore important issues in the follow-up of adenomyoepithelial lesions.
\end{abstract}

Key Words: Breast neoplasms, Adenosis, Myoepithelial tumor

\section{INTRODUCTION}

Hyperplastic and neoplastic lesions of the breast usually arise from atypical proliferation of epithelial cells (1). Hyperplasia of myoepithelialcells isfound in myoepitheliosis to myoepithelial carcinoma (2). Adenomyoepithelial adenosis of breast is a rare variant of adenosis, with similarity to microglandular adenosis, contrary to the presence of myoepithelial cells in significant number. Adenomyoepithelial adenosis exhibits high proliferation in both glandular and myoepithelial component with a tendency to carcinomatous transformation $(2,3)$. It can be a well-circumscribed lesion or may consist of multifocal randomly arranged ductules. The asynchronus hypertrophy and alteration of epithelial and myoepithelial cells is a characteristic of adenomyoepithelial adenosis (4). A case of adenomyoepithelial adenosis is reported and discussed on the basis of clinical, radiological, and pathological findings in this article.

\section{CASE REPORT}

A 17-year-old female sought attention for her breast lump, two months after her first notice. She was non-lactating. Family history was noncontributory. Physical examination revealed a single well-defined lump in the lower inner quadrant of the right breast with no evidence of associated axillary lymphadenopathy and normal contralateral breast. The tumor had a firm consistency. Routine laboratory test results were all within reference range. Breast sonography revealed a hypoechoic tumor with microcalcification. Mammography showed an opaque mass with linear microcalcifications and focal blurred margin in the right breast. Excisional biopsy was performed as there is chance of malignant change.

Gross examination of the surgical specimen disclosed a well-delineated oval nodule that measured $2.7 \times 2.2 \mathrm{~cm}$ (Figure 1). All of the tissue was formalin fixed (10\%) and processed for paraffin sections. Sections were stained with H\&E and immunohistochemistry with alfa smooth muscle actin and p-63 was done.

On light microscopic examination, the tumor was welldemarcated and composed of biphasic proliferation of glandular epithelial cells and surrounding myoepithelial cells (Figure 2A). Proliferative epithelial cells displayed tubular growth patterns. Prominent myoepithelial cells with clear cytoplasm surrounding the ductal epithelial cells were noted (Figure 2 B,C). There was a prominent focal hyperplastic myoepithelial cell layer with strikingly clear cytoplasm. Both epithelial and myoepithelial cells were blended without cytological atypia. Less than 1 mitosis /10 high power field (HPF) was noted in the mitotic activity. Foci of disorderly arranged glands with mild variation in shape and size with eosinophilic secretion was noted. Immunohistochemical staining of myoepithelial cells was strongly positive (Strong staining pattern) for alfa smooth muscle actin (Figure $3 \mathrm{~A}, \mathrm{~B}$ ) and for p-63 (Figure $3 \mathrm{C}, \mathrm{D}$ ).

The results further supported the existence of myoepithelial cells around the glandular cells. The final diagnosis was adenomyoepithelial adenosis. The resection margins were free. Postoperative course was smooth and uneventful. No additional treatment was performed.
(Turk Patoloji Derg 2017, 33:240-243)

Received : 29.01.2012 Accepted : 17.03.2012
Correspondence: Bhaskar MITRA

Department of Pathology, Midnapore Medical College, Paschim Medinipore, WEST BENGAL, INDIA

E-mail: bhaskarmitra12@rediffmail.com Phone: +91 3325642106 


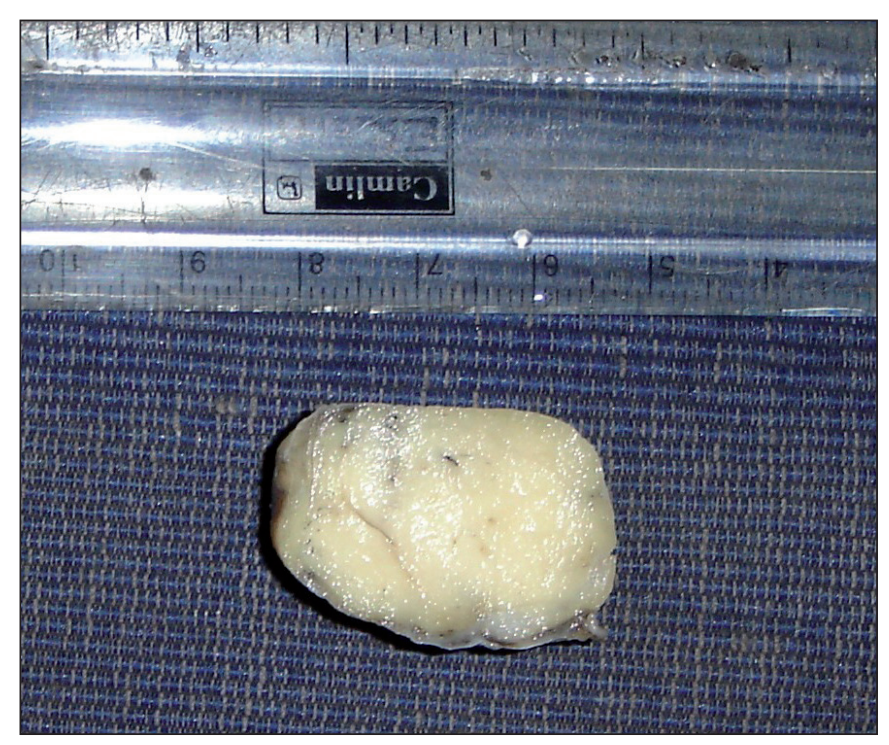

Figure 1: Gross picture of the specimen.

\section{DISCUSSION}

The combined proliferation of epithelial and myoepithelial cells is common in breast- e.g. papilloma and sclerosing adenosis. In adenomyoepithelial adenosis, myoepithelial proliferation is marked. Many lesions, namely, adenoid cystic carcinoma, myoepitheliosis, pleomorphic adenoma, adenomyoepithelial adenosis and adenomyoepithelioma, are composed of myoepithelial cells. Adenomyoepithelial lesions are commonly seen in the salivary gland, skin, and parathyroid $(5,6)$. Myoepithelial cells are usually situated between the luminal ductal epithelial cells and the basal lamina. Tavassoli (3) classified the myoepithelial lesions of the breast as myoepitheliosis, adenomyoepithelioma, and malignant myoepithelioma (myoepithelial carcinoma). Tavassoli has proposed the term myoepitheliosis to describe a process that in its typical form involves the peripheral duct system and is characterized by subepitheilal proliferation of round or spindle shaped myoepithelial cells. She also subdivided adenomyoepitheliomas according to their cell predominance as spindle cells, tubular, lobulated, and carcinoma arising in adenomyoepithelioma. Pia-Foschini et al. (7) suggested that in spite of using the term apocrine adenosis (adenomyoepithelial adenosis) these lesions can be referred as tubular adenomyoepithelioma. Moinfar (4) described adenomyoepithelial adenosis as a rare type of adenosis with a predominance of myoepithelial component. The tubules exhibit an increase in myoepithelial cell infrequently showing enlarged nuclei and prominent nucleoli. Apocrine or squamous metaplasia can be present $(2,4)$.
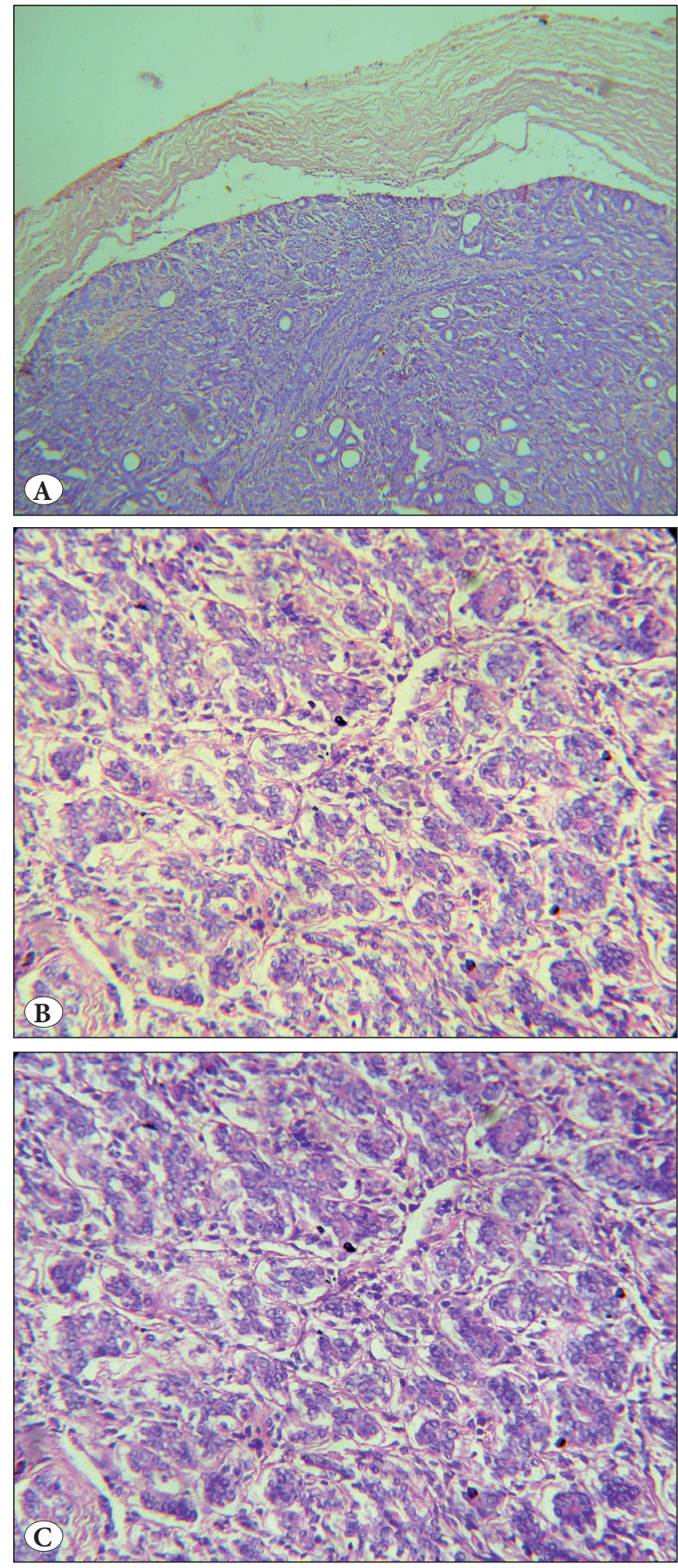

Figure 2: A) A well-demarcated tumor composed of biphasic proliferation of glandular epithelial cells and surrounding myoepithelial cells showing mostly tubular pattern (H\&E; x10). B,C) Proliferative epithelial cells displaying tubular growth patterns with prominent myoepithelial cells with clear cytoplasm around epithelial cells were noted (H\&E; x40). 

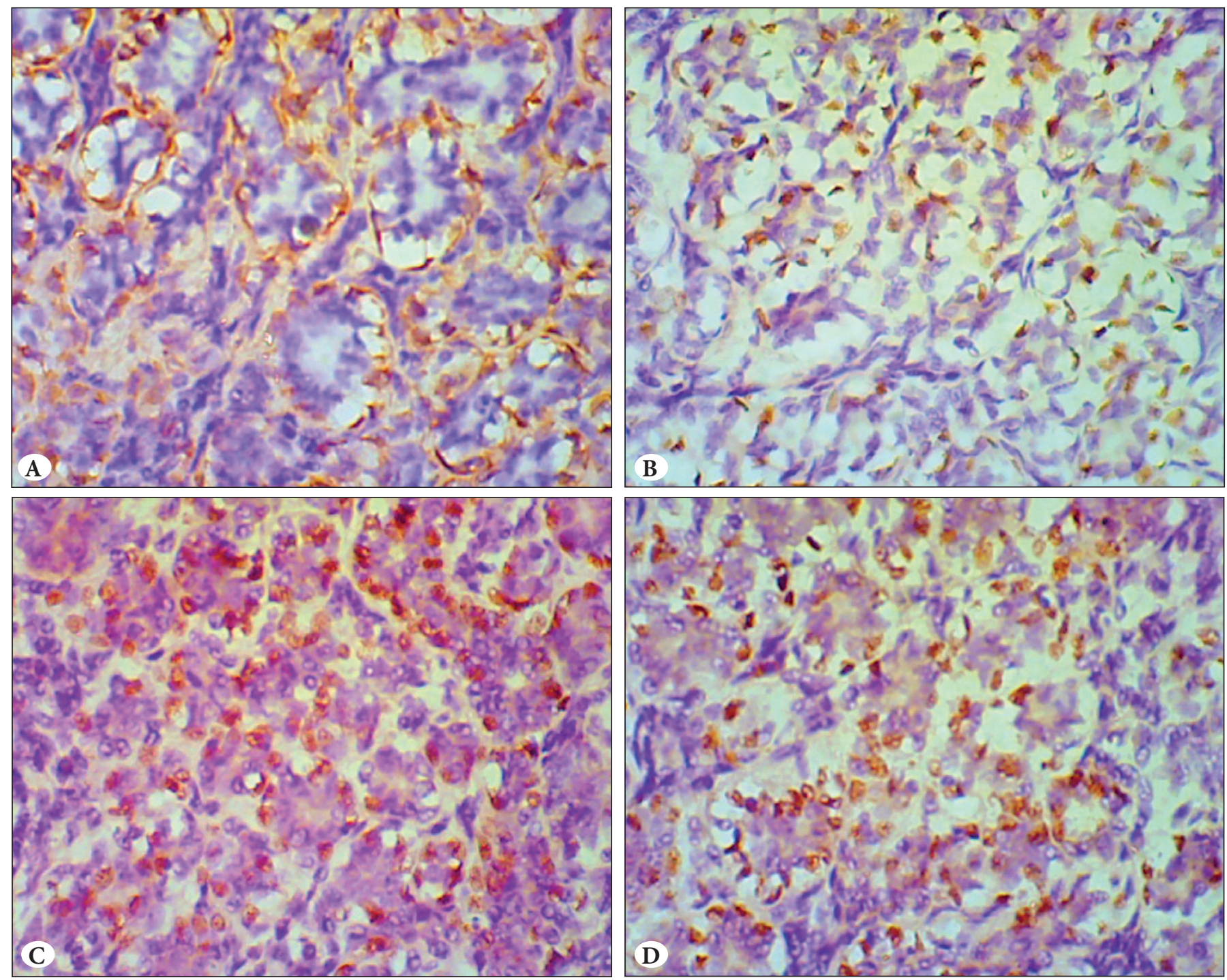

Figure 3: A,B) Strong staining pattern for alpha smooth muscle actin of myoepithelial cells (SMA; $\mathrm{x})$. C,D) Strong staining pattern for p-63 of myoepithelial cells (p63; $\mathrm{x})$.

As per Erel et al. (8) in a 46-year-old female presenting with a breast lump, excisional biopsy showed adenomyoepithelial adenosis. Similarly, a case was reported by Kiaer et al. (9) in a 46-year-old lady with an upper lateral quadrant right breast mass of 2-cm size and biopsy revealed adenomyoepithelial adenosis. But in our case the patient is younger than the previously reported cases.

In our case, the lesion, marked with cellular heterogeneity and associated hypertrophy of epithelial and myoepithelial cells, proves itself as benign in nature. So presence of myoepithelial cells is very much important. In immunohistochemical staining, cytoplasmic positivity by SMA and nuclear positivity of p63 reinforces the myoepithelial cells. In our case both markers showed Grade IV staining pattern (Figure 4,5).
Adenomyoepithelial adenosis (AA) is histologically indistinguishable from a small (microscopic) adenomyoepithelioma (AME) (4). In most described cases, (AA) blends with or surrounds an (AME). Mammary acini, with ductal epithelial cells as inner lining and circumscribed, prominent, phenotypically variant, and usually solid proliferating, myoepithelial cells outside, are typical histological features of a benign adenomyoepithelioma (1). The myoepithelial cells usually have clear cytoplasm with immunopositivity for smooth muscle myosin, and actin (10). Some show apocrine snouts. Where as in AA, presence of focal proliferation of myoepithelial cell with strikingly clear cytoplasm, which is noted in our case, is usually observed. Histologicaly the AA and microglandular adenosis (MA) are similar and distinguished by absence of myoepithelial cells in the 
latter. Tubular carcinoma with irregular tubules of varying size, shape and distribution is also a in differential diagnosis. The glands of the tubular carcinoma are larger than those of MA and larger than those of AA and show characteristic angular pattern. The lining cuboidal to columnar cells show apical snouts but myoepithelial cells are absent. Desmoplastic stroma, a hallmark feature of tubular carcinoma, is absent in AA and MA (11).

The prognosis of patients with adenomyoepithelial adenosis of the breast is usually good. Behavior of this tumour is uncertain; appear to have low malignant potential with a tendency for local recurrence or rarely metastasis due to failure to achieve a free resection margin. Therefore, it is important to make an accurate pathologic diagnosis and arrange proper management for this kind of rare breast tumor. Further clinical and pathological investigations of breast adenomyoepithelial adenosis may help to elucidate the true nature of this rare tumor.

\section{ACKNOWLEDGEMENT}

There is no conflict of interest related to the work in this study. Written consent has been taken from the subject and from her guardian.

\section{FUNDING SOURCE}

The source of funding was Institutional funds of Midnapore Medical College \& Hospital, Paschim Medinipur.

\section{REFERENCES}

1. Rosen PP. Adenomyoepithelioma of the breast. Hum Pathol. 1987;18:1232-7.

2. Tsuda H, Mukai K, Fukutomi T, Hirohashi S. Malignant progression of adenomyoepithelial adenosis of the breast. Pathol Int. 1994;44:475-9.

3. Tavassoli FA. Myoepithelial lesions of the breast. Myoepitheliosis, adenomyoepithelioma, and myoepithelial carcinoma. Am J Surg Pathol. 1991;15:554-68.

4. Moinfar F. Adenosis. In: Moinfar F, editor: Essentials of diagnostic breast pathology. Berlin: Springer; 2007. 31.

5. Tsuji N, Tateishi R, Ishiguro S, Terao T, Higashiyama M. Adenomyoepitheloma of the lung. Am J Surg Pathol. 1995; 19:956-62.

6. Sciubba JJ, Brannon RB. Myoepithelioma of salivary glands: Report of 23 cases. Cancer. 1982;49:562-72.

7. Pia-Foschini M, Reis-Filho JS, Eusebi V, Lakhani SR. Salivary gland-like tumours of the breast: Surgical and molecular pathology. J Clin Pathol. 2003;56:497-506.

8. Erel S, Tuncbilek I, Kismet K, Kilicoglu B. Adenomyoepithelial adenosis of the breast: Clinical, radiological, and pathological findings for differential diagnosis. Breast Care. 2008;3:427-30.

9. Kiaer H, Nielsen B, Paulsen S, Sørensen IM, Dyreborg U, BlichertToft M. Adenomyoepithelial adenosis and low-grade malignant adenomyoepithelioma of the breast. Virchows Arch A Pathol Anat Histopathol. 1984;405:55-67.

10. Rosen PP. Myoepithelial neoplasms. In Rosen PP, editor: Rosen's breast pathology. Philadelphia: Lippincott Williams and Wilkins; 2001. 121-38.

11. Eusebi V, Foschchini MP, Betts CM. Microglandular adenosis, apocrine adenosis, and tubular carcinoma of the breast. An immunohistochemical comparison. Am J Surg Pathol. 1993;17:99-109. 